\title{
Dr. Chen-lu Tsou: a tireless advocate for advancement in the standards of scientific research in China
}

\author{
Chih-chen Wang ${ }^{1}$, Zhi-Xin Wang ${ }^{1,2}$, Baoyuan Zhang ${ }^{3}$, Ming $\mathrm{Li}^{3}$ \\ ${ }^{1}$ Institute of Biophysics, Chinese Academy of Sciences, Beijing 100101, China \\ 2 School of Life Sciences, Tsinghua University, Beijing 100084, China \\ ${ }^{3}$ Beijing Institutes of Life Science, Chinese Academy of Sciences, Beijing 100101, China
}

The history of modern science in China is relatively short compared to that in western countries. For example, it was not until the 1920s that genetics and evolutionary theory were introduced to China. Most of the earliest Chinese biologists were trained overseas and returned to their beloved homeland to become pioneers of biomedical disciplines like zoology, plant biology, physiology, and neuroscience in China. Those who returned in the 1940s focused more on biochemistry, and after "Reform and Opening" in the late 1970s, molecular biology gradually thrived. With the continuous efforts of numerous Chinese biologists, modern biology started to flourish steadily despite a history of wars and political turbulence. However, even though Chinese biologists trained overseas brought back new knowledge and perspectives to China, the overall system of modern biology in China was still young, and many issues in scientific practice started to appear as time went by. One of them was lack of high academic standards.

For years, the lack of academic standards, especially the lack of scientific writing standards, had been ignored by many Chinese scientists. It is commonly accepted that scientists must not only "do" science, but also "write" science. "Writing" science allows original scientific research to be reviewed by peer scientists, and once approved, to be added to the existing database of scientific knowledge. Global visibility and accessibility of scientific work is particularly important for the basic sciences. For science conducted in China, what this means is that they should be published in English-the universal scientific language -in internationally distributed journals. However, the society of Chinese biologists was once a "closed box" and there was little intellectual exchange with western countries. Most research findings were published in Chinese in scientific journals in China. No matter how novel and important the work, the international scientific community did not get the chance to learn about, appreciate, and review them. Additionally, many scientists and young students never received formal professional training on scientific writing standards, which were strictly followed in western scientific societies. This situation continued for years until a Chinese biochemist, Dr. Chen-lu Tsou, spoke out and advocated applying internationally approved scientific writing standards in China.

Born in 1923, Dr. Chen-lu Tsou, received a Ph.D. degree at the University of Cambridge, UK, in 1951. He worked on protein functions during his entire academic career and pioneered the structure-function study of enzymes using partial proteolysis. He was also one of the few Chinese biologists who had published in Nature in the early years.

As early as the 1980s, Dr. Tsou started to publicly advocate scientific writing standards. He believed that Chinese scientists must publish their basic research results in

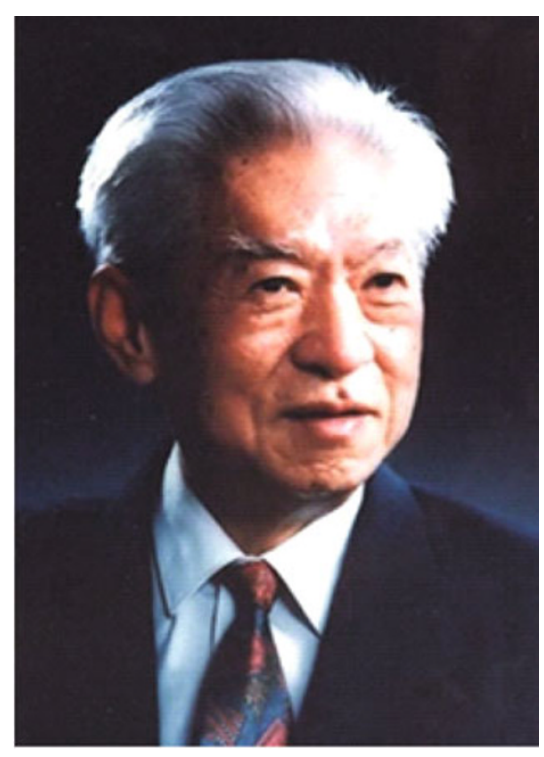

Dr. Chen-lu Tsou (1923-2006) 
internationally renowned peer-reviewed journals to make China's scientific research known to the world. Furthermore, Chinese scientists have to follow international standards of scientific publishing and change their unethical conducts to gain respect in the international scientific community. For example, in order to attract more papers, many domestic journals often encouraged authors to submit their previous publications with minor modifications which is known as "multiple submission" and strictly forbidden in the West. In addition, many authors often incorrectly claimed to be the first to find something without adequate literature research in the field. This not only showed disregard and disrespect towards the achievements of predecessors, but also led them to be ridiculed for ignorance by international colleagues. Furthermore, some supervisors signed their name on articles written by their students and sent them for publication without spending time and effort in ensuring proper quality. They neglected the fact that signing means responsibility, and advisors must be responsible for any omissions or errors in the articles they are co-authors in. Additionally, some researchers directly quoted others' results with the wrong interpretation and non-standard conversion of physical units. Due to such problems, Dr. Tsou suggested that we should change these attitudes in principal investigators (PIs) and promote academic writing standards to graduate students to lay a solid foundation for their research career. Dr. Tsou actively promoted these ideas not only to his peers but also to his students when he taught at the Graduate School of Chinese Academy of Sciences (CAS).

Dr. Tsou also insisted that Chinese journals should become more international, and this was as important as publishing manuscripts in internationally renowned journals. On one hand, China should publish more English journals independently, which is the first step to internationalization. On the other hand, it is necessary to apply internationally approved scientific writing standards and the peer-review process to journals published in China. In this way, China's scientific research and Chinese scientific journals can both get more attention from international scientists, which will in turn lead to the promotion of high academic standards in China.

In the past twenty years, China has made significant progress in these two fronts. The importance of high academic writing standards has been widely acknowledged in various scientific and technological fields in China. Increasingly more Chinese scientists have published highquality papers in international academic journals. According to some recent statistics, the total number of scientific publications from China sky-rocketed and ranked No. 2 in the world in 2010, and the total citation number of scientific publications moved up to No.8 in the world. In addition, the influence of international English journals published in China has been growing. Most if not all of these positive changes can be ascribed one way or another to Dr. Tsou's tireless advocacy of high scientific standards in China. His continued efforts won the respect of many researchers, and he has no doubt played a vital role in creating a favourable academic environment for scientific research in China.

Dr. Tsou passed away in 2006 , but his contribution has left a profound impression on young people of every generation. His articles on academic ethics and norms have been included in The Selection of Excellent Tutor Experience in the Graduate School of the Chinese Academy of Sciences, and have always been viewed as the guideline for all the CAS graduates. Dr. Tsou's contribution to pushing China's academic standards several notches higher will be remembered forever. We are soberly aware of the gap between China and developed countries in science and technology, and there is a long way ahead to strive and persist in. 